\title{
¿ADVERSUS IUDAEOS O PROCONVERSO? TEOLOGÍA PROCONVERSA EN LA CUARTA PARTE DE LA INTRODUCCIÓN DEL SIMBOLO DE LA FE (1583)*
}

\author{
POR
}

\author{
AXEL KAPLAN SZYLD ${ }^{1}$ \\ Universidad de Bar-llan
}

\section{RESUMEN}

Mediante la adopción de una interpretación performativa de la Cuarta parte de la Introducción del símbolo de la fe, de fray Luis de Granada, mostraré que bajo las apariencias de un tratado antijudío (que seguiría la larga tradición de escritos adversus iudaeos) se esconde un catecismo proconverso. Analizando algunos de sus motivos como son la "ceguera judaica», la "caridad cristiana», el binomio honra-deshonra, y destacando la importancia de las enseñanzas de San Pablo en aquella obra, mostraré que fue un alegato político y espiritual para defender la integración de los judeoconversos.

PALABRAS CLAVE: fray Luis de Granada; paulinismo; cristianos nuevos; Inquisición.

\section{ADVERSUS IUDAEOS OR «PRO CONVERSO"?: PRO CONVERSO THEOLOGY IN THE FOURTH PART OF THE INTRODUCTION OF THE SYMBOL OF THE FAITH (1583)}

\begin{abstract}
By endorsing a performative interpretation of the Fourth Part of the Introduction of the Symbol of the Faith of Friar Luis de Granada I will argue that, beyond the appearances of an anti-Jewish tract (written after the long-lasting tradition of Adversus ludaeos), lay a catechism written in favor of the Conversos. After studying some of the motifs in the book (e.g. "Jewish blindness", "Christian charity» and the couple "honor and dishonor») and revealing its Paulinian penchants, I will show that the book was conceived as a political and spiritual manifesto on behalf of Converso integration.
\end{abstract}

KEY WORDS: fray Luis of Granada; Paulinism; New Christians; Inquisition.

Cómo CITAR ESTE ARTículo / CITATION: Kaplan Szyld, Axel. 2020. «¿Adversus iudaeos o proconverso? Teología proconversa en la Cuarta parte de la Introducción del símbolo de la fe (1583)». Hispania Sacra LXXII, 146: 377-389. https://doi.org/10.3989/hs.2020.026

\author{
Recibido/Received 01-02-2018 \\ Aceptado/Accepted 30-03-2018
}

En el presente artículo trataré de habilitar un enfoque de la Cuarta parte de la Introducción del símbolo de la fe (Salamanca, 1583) (en adelante la Cuarta parte), ${ }^{2}$ escrita

*Esta investigación fue realizada con el apoyo de: 1. Doctora Fellowships of Excellence Program of the University of Bar-Ilan; 2. The Council for Higher Education, Scholarships in memory of Nathan Rotenstreich; 3. I-CORE Program of the Planning and Budgeting Committee and The Israel Science Foundation (grant No. 1742/12)

axel.kaplan@live.biu.ac.il /

ORCID iD: https://orcid.org/0000-0002-3652-1137

2 Quarta parte de la Introduction al symbolo de la fe: en la qual (procediendo por lumbre de fe) se trata del mysterio de nuestra Redemption: para lo cual se traen todas las prophecias, que testifican ser Christo nuestro salvador el Mesias prometido en la ley, donde también se declaran otros misterios, y artículos de nuestra Santa Fe, en Portugal por el místico dominicano fray Luis de Granada (1504-1588), ${ }^{3}$ como un catecismo dirigido especialmente

contenidos en el símbolo, Compuesta por el R.P Maestro F. Luys de Granada de la Orden de Sancto Domingo, en Salamanca por los herederos de Mathias Gast, M.D LXXXIII (de ahora en adelante, Luis de Granada 1583).

3 Luis de Sarriá nace en Granada, en una familia pobre, y queda huérfano de padre tempranamente. Tuvo la suerte -otros dirán la providencia - de ser adoptado por el conde de Tendilla, don Iñigo López de Mendoza y Quiñones, para servir como paje de sus nietos. Junto con ellos cursó sus primeros estudios en las «escuelas de la doctrina» fundadas por el arzobispo de Granada, Hernando de Talavera. En 1523 entró en el convento de dominicos de Santa Cruz, donde hizo profesión dos años más tarde. Por su capacidad intelectual, y después de haber sido atestiguada su limpieza de sangre, recibe en 1529 
al público judeoconverso. Esto ocurre en tiempos donde la vía catequética-evangelizadora, como medio para resolver el problema converso, se encontraba en contradicción con la voluntad de la mayoría del alto clero portugués. ${ }^{4} \mathrm{~A}$ partir de un análisis de la argumentación del tratado intentaré demostrar que, a pesar de la naturaleza antijudía del texto que nos ocupa, tanto temática como hermenéuticamente, la Cuarta parte se elaboró basándose en una arraigada teología paulina proconversa, tradición teológica y apologética que fue desarrollada durante el siglo XV por autores como Pablo de Santa María, Alonso de Cartagena, Alonso de Oropesa o Hernando de Talavera. ${ }^{5}$ De esta manera, se verá que la Cuarta parte fue una alternativa misionera y catequética frente a la represión religiosa y la exclusión social de los «cristãos-novos» promovidas por la Inquisición y los Estatutos de limpieza de sangre. ${ }^{6}$

\section{LA CUARTA PARTE DE LA INTRODUCCIÓN DEL SÍMBOLO DE LA FE}

A pesar de que la Introducción del Símbolo de la fe es reconocida como la obra cumbre del dominico, los investigadores se han concentrado en la primera parte de la misma. ${ }^{7}$ La Cuarta parte aquí tratada no ha tenido aún sufi-

una vacante para ingresar en el prestigioso colegio San Gregorio de Valladolid. Aquí es donde entablará su amistad con el futuro arzobispo de Toledo Bartolomé de Carranza. En 1534, después de su intento frustrado de viajar a las Indias como misionero, es reclamado en Córdoba para restaurar, con gran éxito, el convento de Scala Coeli. En esa época conoció a Juan de Ávila, quién resultó ser una enorme influencia en el pensamiento del dominico. La segunda etapa de la vida de fray Luis de Granada, llamada por los estudiosos la etapa lusitana, comienza a principios de 1551, con el pase de este a Portugal (Évora) como capeIlán del cardenal infante Henrique (inquisidor general 1539-1579, rey de Portugal 1578-1580). En 1556 es elegido provincial de su orden. Ya en 1554 el dominico saca a la luz su primer best seller, el Libro de la oración y meditación (Salamanca, Portonaris, 1554). Tres años después estrena su segundo éxito espiritual, la Guía de pecadores (Lisboa, Blauio de Colonia, 1557). Estas dos obras, que transformaron a nuestro autor en un grande de la literatura espiritual, también lo pusieron en un aprieto con el Santo Oficio, ya que en 1559 estos libros se implantan en el Index librorum prohibitorum, creado por el inquisidor general Fernando Valdés, y auspiciado por el teólogo Melchor Cano. La prohibición de sus libros no detiene al dominico, puesto que el mismo año se publica el Compendio de doctrina cristiana (Lisboa, loannes Blavio de Colonia, 1559) siendo este un manual, un catecismo, con el propósito de adoctrinar y mejorar la situación de ignorancia de los curas y predicadores portugueses. A estas obras, se les suma su tratado cumbre: Introducción del símbolo de la fe, en sus cinco partes, publicada hacia el final de su vida, en 1583. Fallece en Lisboa a finales de 1588. Una lista completa de su obra, junto con los datos aquí expuestos, se encuentra en Huerga 1988a; Alonso del Campo 2005. Un ejemplo del énfasis puesto por parte de los investigadores en sus orígenes de cristiano viejo se encuentra en Balcells 1989, 13-14, 16. Una posible explicación del fenómeno se podrá hallar en Ingram 2009, 350-351.Véase, además, Huerga 1949, 434-480; 1950, 293-335. La pregunta «fray Luis de Granada, ¿cristiano viejo o nuevo?» no nos ocupa en este artículo.

4 Baião 1906, 39-42; Marcocci y Paiva 2016, 69-71.

Para el fenómeno del paulinismo converso (o proconverso) véase, entre otros, Bataillon 2013; Pastore 2010; Rosenstock 2002; Giordano 2004; Stuczynski 2012, 151-177 y 2020.

6 Sigue siendo imprescindible para la temática Sicroff 2010, y más recientemente Hernández Franco 1996 y 2011. Para el caso portugués véase Figueirôa Rêgo 2011.

Edición crítica Balcells 1989. Además, véase, entre otros, Llamas Inglés 1998; Alsina Calves 1999, 337-345; García García 2016, 611-638. ciente atención de la investigación. ${ }^{8}$ Esto se debe a que, si bien fray Luis es reconocido como una de las grandes figuras del humanismo cristiano y del misticismo católico español (inclusive anterior a Teresa de Ávila, Luis de León o Juan de la Cruz), la investigación se ha centrado en sus aspectos místicos y espirituales, ponderando sus aportes literarios y lingüísticos, dejando en segundo plano su actividad política y eclesiológica como un hombre de su época. ${ }^{9}$ En otras palabras, la imagen dominante que se otorga a fray Luis de Granada por una larga tradición de tenor hagiográfico es la de un autor inmerso en la vita contemplativa y no en la vita activa. Quizás esta sea una de las razones que expliquen el motivo de la ausencia, o falta de atención, que recibió el tema judeoconverso en su obra, cuestión que emerge fuertemente en su Cuarta parte.

La obra cumbre de Luis de Granada, Introducción del Símbolo de la Fe, con sus cuatro partes, se escribió en Portugal y fue publicada por primera vez en Salamanca por los herederos de Mathias Gast en el año 1583. La primera parte del libro trata de la creación del mundo. La segunda, de las excelencias de la religión cristiana. La tercera y la cuarta tratan del misterio de la redención, pero desde distintas perspectivas: la tercera parte trae argumentos correspondientes a la lumbre de razón para demostrar que la pasión de Cristo fue el principal y único camino para la salvación de la humanidad; en cambio, la cuarta intenta mostrar por lumbre de fe, con el apoyo de las Sagradas Escrituras y sus profetas, que Jesucristo es el mesías prometido por el Antiguo Testamento. ${ }^{10}$

La Cuarta parte se divide en dos partes. La primera contiene veintiún capítulos en los cuales, con la ayuda del Antiguo Testamento, se busca probar que Cristo es el mesías prometido en la ley mosaica. ${ }^{11}$ Sus primeros ocho capítulos sirven de introducción teológica. Su propósito es declarar, con la ayuda de profecías veterotestamentarias, las circunstancias y tiempo exacto de la venida de Cristo al mundo,

8 Además de las páginas dedicadas por Resina Rodrigues en su estudio (1988, 381-406), se encuentra un artículo de Blanca Vizán $(2013,195-216)$ que se centra en el apartado «de las mentiras, desvaríos y falsedades del Talmud», como razón principal de la amplia lectura de la Cuarta parte por el público judaizante. En este momento me encuentro escribiendo un estudio sobre estas lecturas subversivas.

9 Acerca de la espiritualidad de fray Luis y de su obra, véase el estudio de Resina Rodrigues ya citado, y más recientemente Borges 2009, 135-149. Como ejemplo de sus innovaciones lingüísticas, Gallego Morrel 1993, 231-235; Praena Segura 2005, 107-143.

10 Un año después de la primera edición del libro, se publica por separado un sumario que recibe el nombre de la quinta parte de la obra. En el final de este se encuentra "Un breve tratado en que se declara la manera que se podrá proponer la doctrina de nuestra santa fe y religión cristiana a los nuevos fieles». La investigación ve en estas 50 páginas la expresión más cabal del esfuerzo misionero y catequético del monje, Huerga 1989, 84-85, 148; Alonso del Campo 2005, 181-183, 291; Huerga 1988a, 279. Sin embargo, debo señalar que mientras que este pequeño tratado fue concebido como útil al servicio de la misión al otro lado del mar, yo considero que su gran y elaborado catecismo fue camuflado para no toparse con la censura inquisitorial y poder circular libremente, como la cuarta parte de su obra monumental y voluminosa, véase Kaplan Szyld 2018.

11 Sobre el amor de fray Luis a las Sagradas Escrituras y su afán de traducirlas al romance, Bataillon 2013, 594-600; Huerga 1988a, 56-72, 129-30. Sobre los inconvenientes y dificultades que podrían causar y causaron estas traducciones, véase Martínez de Bujanda 2016, 38-39. Y en el caso de la obra tratada, Liebman 1970, 152-153; Gitlitz 1996, 431, 435-436; Bodian, 2007, 57, 68-69, 150; Vizán 2013, 195-216. 
sus cualidades humanas y divinas, y, por supuesto, su pasión y resurrección redentoras. Luego se pasa a la porción central de esta primera sección, esto es, a la descripción de las cuatro hazañas (correspondientes a la parte histórica del tratado, viniendo a ser el cumplimiento de las profecías anteriormente analizadas), las cuales tendrían que ocurrir posteriormente a su venida. Las tres primeras hazañas exhiben el fin de la idolatría, la mudanza de los gentiles al monoteísmo y su entrada a la moral cristiana (todos frutos de la Pasión). Estas, claramente, representan la fase infantil de la humanidad gentilicia antes de la venida de Jesucristo, fase que acabara con su llegada al mundo y con el traspaso de su gracia a un plano universal. Igualmente, la más extensa y detallada de las hazañas, que ocupa casi toda esta parte, es «la cuarta Hazaña que se auia de seguir despues dela muerte del Salvador, que fue el castigo famoso de los que se la procuraron $"{ }^{12}$ Aquí, fray Luis muestra que Dios abandonó a su pueblo elegido para expandir su gracia a toda la humanidad. Partiendo de un punto de vista teológico hermenéutico, se busca conmover al lector con el relato de los sufrimientos y atrocidades que persiguen a los judíos que no han recibido a Cristo. Sin embargo, el dominico enfatiza el rol pedagógico del pueblo hebreo. No solamente por ser este el pueblo elegido por Dios, del cual surgiría el Mesías, sino debido a que la historia del pueblo de Israel reflejaba un fragmento inseparable del misterio de la salvaciónredención mundial (de la cual también su ceguedad los hace partícipes, cosa recordada por el dominico ad nauseam por toda la obra). ${ }^{13}$ Tanto los cultos exteriores y sacrificios de la ley mosaica como los castigos sufridos por los hebreos eran necesarios para poder llegar a la ley formada de gloria y gracia de Jesucristo, ${ }^{14}$ siendo la meta final la unión de los judíos y gentiles bajo una sola fe.

La segunda parte del catecismo está formada de once capítulos Ilamados diálogos, en los cuales el maestro aclara las dudas y misterios de la doctrina cristiana a su alumno (catecúmeno), recientemente convertido del judaísmo. Ahora bien, sostengo que estos diálogos revelan el propósito profundo de fray Luis: ofrecer un libro que sirva para adoctrinar a los judeoconversos. $Y$ es que, al contrario de lo que podría esperarse en un catecismo dirigido a los judíos, en el cual se utilizan los argumentos clásicos de la tradición literaria antirrabínica (adversus iudaeos) (esto es, polemizar contra las mentiras y falsedades del Talmud), aquí el maestro aborda las temáticas que más incomodaban al público ya bautizado de su tiempo. ${ }^{15}$ Por ejemplo,

12 Luis de Granada 1583. La hazaña ocupa los capítulos XIII-XX extendiéndose desde el folio 53 hasta el 101.

13 Véase la función que le otorga Hernando de Talavera en su Católica Impugnación al pueblo de Israel, Giordano 2018, 94-110.

14 Por todo el texto se encuentran alusiones como la siguiente: «Porque aquellos no tenian mas que las sombras, nosotros tenemos la luz: aquellos la figuras, nosotros la verdad, aquellos la ley, nosotros el Euangelio, aquellos la letra que mata, nosotros el espíritu que da vida, aquellos los sacrificios de los animales, nosotros el sacrificio del verdadero cordero que es Christo...», Luis de Granada 1583, 211. Sobre las diferencias entre el lugar eclesiológico o soteriológico que puede adoptar el judío (y converso) en la polémica proconversa, Stuczynski 2020.

15 Tanto para la formación de la polémica antijudía alrededor de los Patres ecclesiae, como para su estado y características en el ocaso del medievo y comienzos de la modernidad, véase Cohen 1982, y del mismo autor 1999. Al comienzo de la segunda parte se encuentra un capítulo, De las mentiras, falsedades, y desuarios del Talmud, el cual la humanidad (y divinidad) de Jesucristo (diálogos 2, 3, 4), la pobreza, humildad (diálogo 5), aspereza y trabajos ocurridos durante su vida (diálogo 6) y su pasión (diálogo 7). Junto a los coloquios de tono cristológico, se encuentran diálogos de otra naturaleza que tratan «de la derogacion de los sacrificios y ceremonias de la ley» (diálogo 9) y de "la ceguedad, y miserias, que viuen la parte de los ludios que no ha recibido la Fe del Saluador» (diálogo 10). Para terminar, se encuentra un diálogo que compara la iglesia primitiva judeocristiana con la actual (diálogo 11). ${ }^{16}$ En estos coloquios, fray Luis pone en boca de su maestro, auténtico heraldo paulino, ${ }^{17}$ argumentos proconversos con la intención de reconciliar al judeoconverso con la religión y sociedad cristiana.

Antes de penetrar en la obra, es de fundamental importancia comprender el contexto en la cual se publicó. Es necesario explicar la problemática que produce un catecismo de naturaleza proconversa, es decir, el debate mantenido sobre la capacidad de adoctrinamiento del público cristiano nuevo, siendo parte de ellos sospechosos de ser herejes judaizantes.

\section{¿ADVERSUS IUDAEOS O PROCONVERSO?}

Se debe recordar que la obra tratada se publicó en el año 1583, casi pasada una centuria de la expulsión de los judíos de España y de los bautismos forzados de Portugal. ¿Quiénes son esos iudios a los cuales fray Luis se dirige? Sugiero que la alusión aquí es a la casta conversa, que seguía siendo culpada de mantener en secreto la religión de sus antepasados. ${ }^{18}$ Como ya fue señalado por la historiografía, el transcurrir del tiempo no logró paralizar el odio contra el

se extiende por solo seis folios (109-115). El espacio que se brinda al capítulo, su lugar en la obra (al principio de la segunda parte, antes de comenzar los diálogos) y el aviso del dominico en su al christiano lector al comienzo de esta parte (en donde aclara que no se tratará sobre los «argumentos de los maestros de ellos», tarea ya tratada por otros "tan claros ingenios», Luis de Granada 1583,3 ) nos hacen pensar que este capítulo es un agregado, un "forzado» en esta obra. Además, es fácil darse cuenta de que el dominico no penetró en el tema, solo se sirvió del tratado y de los topoi del converso Jerónimo de Santa Fe (ed. Orfali 1987). Creemos que el monje tuvo en frente la traducción al portugués de este, ordenada por D. Gaspar arzobispo de Goa en 1565, véase Santa Fe (ed. Orfali) 2014. Para un razonamiento distinto, Resina Rodrigues 1988, 863-868.

16 Al comienzo del décimo diálogo fray Luis se expande sobre la grandeza de la iglesia primitiva formada por apóstoles y obispos hebreos. El relato pone énfasis principalmente «en la pureza y perfección de los que creyeron de la circuncisión», véase Luis de Granada 1583, 192-195. La iglesia del tiempo del dominico, tratada en el coloquio número once, vendría a ser una antítesis de la última. La importancia de los primeros creyentes de origen judío es un tópico en la monumental Apología del francés Henri Mauroy, véase Sicroff 2010, 216-218. Claude B. Stuczynski, con la ayuda de Nadia Zeldes, se encuentra trabajando en este texto proconverso.

17 Según su biógrafo, es durante su estadía en el monasterio de Scala Coeli donde acontece la crisis espiritual que lleva a fray Luis a comprender que no conocía al verdadero Cristo, Huerga 1988a, 64-74. Es ahí, durante su estadía en Córdoba, donde el dominico comprende que el Mesías no se encontraba en la escolástica aprendida en San Gregorio de Valladolid, sino que este moraba en sus creyentes, los cuales purificaba con su gracia. Volveré a desarrollar el tema a continuación.

18 La asimilación del judío con el converso (o judaizante) es una idea que sobresale dentro de la obra ya citada de Sicroff. 
grupo mencionado, por el contrario, agravó la persecución y segregación hacia los mismos. ${ }^{19}$

Junto con la implantación de la Inquisición en Portugal, se efectuaron escasos intentos de adoctrinamiento del público converso, con la ayuda de catecismos elaborados especialmente para ellos. ${ }^{20}$ Dentro de estos se puede nombrar el Espelho de Christãos Novos, de Francisco Machado; ${ }^{21}$ los tratados antirrabínicos de João de Barros, ${ }^{22}$ y la obra Inquisição e Segredos da Fé, de Diogo de Sá. ${ }^{23}$ Se debe hacer hincapié en la palabra intentos, debido a que, a pesar de estar parte de los tratados dedicados al cardenal infante Henrique en persona, este y la censura manejada por él no vieron propicio publicarlos. ${ }^{24}$ La negativa del infante hacia esta vía catequética conversa, escrita en romance, provendría de su temor de ser usada por sus lectores para profundizar en su herejía judaizante. Este miedo queda reflejado de manera sistemática en el Index librorum prohibitorum, publicado en 1581 por el inquisidor Jorge Almeida (15791585), donde se reprime todo tratado que ostente algún recuerdo mosaico. ${ }^{25}$ Todo ello nos podría llevar a pensar que la actividad inquisitorial, que entonces afectaba a un creciente número de judaizantes, retroalimentó la desconfianza en el medio catequético. ${ }^{26}$ La creencia del infante Henrique y sus seguidores en la dificultad de enderezar a los presuntos herejes, con medios pedagógicos y catequéticos, se tradujo en un creciente abandono de la acción pastoral.

La necesidad de enseñar la doctrina cristiana a la población conversa, y con ella el debate sobre la legitimidad y beneficio de los textos que la propagan, reaparece con fuerza tras la muerte del infante Henrique. Acercándose el

19 En 1578, pocos años antes de la publicación de la obra, tuvo lugar el llamado "desastre de Alcazarquivir». El hecho de haber sido parte de la aventura costeada por los conversos, lo aprovechó el infante Henrique para justificar una nueva ola de odio hacia los mismos, Caro Baroja 2000-2005, 1: 364-365; Feitler 2015, 86; Azevedo 1922, 131-132; Saraiva 2001, 184,198. Igualmente, como apuntó Rafael Valladares 2008, 245, aún no se elaboró ningún estudio sistemático sobre la cuestión conversa portuguesa durante la crisis sucesoria, conquista y luego anexión del reino.

También el lado español de la península sufre un brote anticonverso con la anexión de Portugal. En varias localidades se encuentra un incremento de causas inquisitoriales «por obrar la ley de Moyses» debido, principalmente, al pase de los conversos portugueses a tierras castellanas, véase Caro Baroja 2000-2005, 1, 474-480; Fernández García 1995, 480-482.

20 Un recuento de estos se encuentra en Talmage 1981, 265-285; Marcocci y Paiva 2016, 52-65.

21 Se termina su redacción en el año 1541, para la edición crítica véase Vieira y Talmage 1977.

22 Me refiero a su Ropica pnefma, publicada en 1532 (censurada más tarde) y editada por Révah en el año 1983. Para la edición crítica de su segundo y famoso tratado redactado cerca de 1543, Dialogo evangélico sobre os Artigos da Fé contra o Talmud dos Judeus' véase Révah 1950.

${ }^{23}$ Redactada circa 1562, un profundo estudio y edición crítica se encuentran en Costa Gomes 2012.

24 Vieira y Talmage 1977, 36; Saraiva 2001, 28; Costa Gomes 2012, 1: 151-152.

25 Feitler 2015, 68. En él también se encuentra el único tratado apologético de Barros que se había salvado del destino de manuscrito, aquí nota número 22.

26 Se debe reconocer que, junto con el temor a las posibles lecturas subversivas, Saraiva 2001, 28, se encuentra en el infante inquisidor una postura anticonversa y proinquisitorial fácilmente palpable; véase, entre otros, Azevedo 1922, 128; Maryks 2010, 120, 139, 250; y principalmente Marcocci 2004. final de la centuria, voces provenientes de los altos rangos inquisitoriales y eclesiásticos, como la del cardenal archiduque Alberto (virrey de Portugal 1583-1593, inquisidor general 1586-1593), vieron la necesidad de un catecismo específico que, fundado principalmente en las «autoridades del Antiguo Testamento», se dirija a los conversos para acabar de introducirlos finalmente en la sociedad cristiana. ${ }^{27}$ Esta vez, la negativa no vino del inquisidor sino de los obispos. Ya años antes de que el archiduque Alberto proponga su iniciativa evangelizadora, el obispo de Portalegre, Frei Amador de Arrais, consagró un capítulo entero de sus Diálogos para refutar la vía catequética. La inutilidad de esta queda reflejada en el mismo título del capítulo quinto de su diálogo tercero: "Que humanamente parece não ter remédio a obstinação dos judeus, per via de disputas \& argumentos». ${ }^{28}$ Parece no haber forma misionera-pedagógica para aquellos «judeus». La solución para ellos vendrá solo del cielo. ${ }^{29}$ Como el infante en su momento, Arrais, lejos de ver estas lecturas como herramientas evangelizadoras, resaltó el terrible daño que infligían las mismas. Esto es, el uso subversivo que recibían estas obras por el público judaizante..$^{30}$

Las actitudes y respuestas negativas a la vía catequética, como la expresada por Frei Arrais, llevaron a los investigadores a sospechar que se dejaron de elaborar obras antijudías con la aspiración de reconciliar a los conversos. ${ }^{31}$ En lugar de ellas, surgen textos que denigran la imagen del judío (que representa al converso), y de este modo consiguen exaltar la ortodoxia portuguesa. Sin embargo, propongo que el escenario fue más variado. Parte de las obras que se escribieron en estos años, incluyendo la Cuarta parte, ofrecieron un modo positivo y pedagógico para afrontar el

27 Véase nota número 4. Feitler 2015, 15-17 muestra que la "situación conversa» preocupó a varias de las entidades eclesiásticas más importantes.

Aunque la propuesta del inquisidor general y virrey de Portugal, el archiduque Alberto, se formuló en 1592, desde los comienzos de la Inquisición portuguesa existió un bando evangelizador y otro represor (la tensión entre las posturas seguirá mucho después, adentrándose en el siglo XVII). Se debe tener en cuenta que la obra aquí estudiada se redactó en Portugal en el año en el cual el archiduque Alberto comenzó su labor de virrey, pero no de inquisidor general, cargo ocupado por Jorge Almeida hasta su muerte, en 1585. Por esta razón creemos que la obra fue dedicada al inquisidor general español, don Gaspar de Quiroga, tomado como «moderado» por la historiografía, Asencio 2000, 68-69; Llorente 2004, 308-317; Maryks 2010, 150. En este caso, como ya intuyó Giuseppe Marcocci (2004, 351 nota 33. Marcocci y Paiva 2016, 70), podríamos ver la Cuarta parte como una anticipación a la preocupación del archiduque Alberto.

28 Arrais 1604 (primera edición 1589), 224.

29 «E não bastando isto, resta que do Ceo lhe venha o remedio, \& que Deos por sua infinita bondade milagrosamente os alumie», Ibídem, 228. La respuesta del obispo de Elvas, Antonio Mattos de Noronha, no difiere mucho de la del obispo de Portalegre: «temo que ha de ser pouco fruito para elles por estarem obstinados e endurecidos em seus errores e tão doutrinados nelles por seus pais e persuadidos, desde que nascem, que ha de ser necessario mui particular fauor de deus pera se apartarem deles», Baião 1906, 41. Una excepción parece ser el obispo de Algarve, Francisco Cano, que pide por medio de la predicación, como la que fue obrada en la iglesia primitiva por Pablo el apóstol - tarea que el Santo Oficio debería ejecutar-, atraer a los cristianos nuevos al Evangelio, ídem.

30 Arrais 1604, 225.

31 Baião 1906, 42; Azevedo 1922, 179-180; Resina Rodrigues 1979. 
problema judeoconverso. Ahora bien, si además de analizar textualmente la obra aquí estudiada, se la examina a partir de su carga performativa, ${ }^{32}$ se revela así la verdadera naturaleza del tratado. En otros términos, si se deja de lado el formato, estilo y apariencia antijudía (adversus iudaeos) de la obra, y se hace hincapié en los argumentos traídos por ella, fijándolos en su contexto, podríamos entenderla como un catecismo proconverso. De esta manera, a pesar de su aparente carácter antijudío, esta obra, interpretada desde su contexto discursivo, revela la voluntad de ofrecer otra realidad posible. Debemos ver la Cuarta parte como una manera de acción y no solo de representación. Frente a nosotros yace la respuesta positiva de fray Luis con respecto al debate de la «cuestión conversa» sostenido en Portugal. Podemos concebir que la Cuarta parte, en el contexto expuesto, pasa a ser un alegato de defensa del público converso, ya que, como demostraré inmediatamente, esta representaba una alternativa misionera-catequética a la represión inquisitorial y a la segregación de los Estatutos de limpieza de sangre. ${ }^{33}$

\section{TEMÁTICAS Y ARGUMENTOS PROCONVERSOS}

\section{Paulinismo}

Fray Luis comienza la Cuarta parte de su Introducción con la citación de Juan $(5,39)$ «Scrutamini scripturas: quia vos putatis in ipsis vitam aeternam habere. Et illae sunt quae testimonium perhibent de me». ${ }^{34}$ Este versículo fue el que inspiró al obispo converso de Burgos, Pablo de Santa María (Shlomo Halevi 1350-1435), para el nombre de su obra Scrutinum Scripturarum. ${ }^{35}$ Este modo de obrar demuestra la línea teológica que seguirá el tratado: el énfasis se colocará en la conexión existente entre el Viejo y el Nuevo Testamento y no en la ruptura entre ellos. En otras palabras, mientras el Antiguo Testamento escolta y pronostica la nueva Ley, esta representa su cumplimiento. Esta elección pone de

32 «...En estos ejemplos parece claro que expresar la oración (por supuesto que en las circunstancias apropiadas) no es describir n hacer aquello que se diría que hago al expresarme así, o enunciar que lo estoy haciendo: es hacerlo... ¿Cómo llamaremos a una oración o a una expresión de este tipo? Propongo denominarla oración realizativa», Austin 1955, 6 (conferencia I). Aprovechamos también la carga histórica que le otorga Quentin Skinner: «My contention, in essence, is that we should start by elucidating the meaning, and hence the subject matter, of the utterances in which we are interested and then turn to the argumentative context of their occurrence to determine how exactly they connect with, or relate to, other utterances concerned with the same subject matter. If we succeed in identifying this context with sufficient accuracy, we can eventually hope to read off what it was that the speaker or writer in whom we are interested was doing in saying what he or she said» Skinner 2002, 116. Para la utilización del método performativo dentro de la temática que nos ocupa, véase Stuczynski 2015, 63-94.

33 No como los otros intentos nombrados, la Introducción (incluyendo la cuarta para de ella) fue impresa en muchas ediciones, alcanzando una extensa difusión, llegando a ser todo un best seller de la época, Rodrigues 1988, 23; Dadson 1998, 51-70.

34 «Escudriñad las Escrituras, porque á vosotros os parece que en ella tenéis la vida eterna; y ellas son las que dan testimonio de mí», Luis de Granada 1583: carátula (traducción de la antigua versión de Casiodoro de Reina, 1569). La mayoría de las ediciones conservan el versículo.

35 Para un estudio de la obra remito a Yisraeli 2014. Coincido con Stuczynski $(2018,2-4)$ en que Santa María es un pionero en lo que concierne al «paulinismo converso». manifiesto la importancia de la conversión de «Israel según la carne» (término paulino para designar al pueblo hebreo) y su lugar especial, tanto en lo referente a la promoción del cristianismo alrededor del mundo, como en el proceso de la salvación-redención universal. ${ }^{36}$

Junto a esta iniciativa, se encuentran otros patrocinios paulinos que acuñó el dominico del obispo de Burgos. Ya en la primera frase de su al christiano lector este efectúa una asimilación con san Pablo, asumiendo textualmente el rol del apóstol: ${ }^{37}$

Era tan grande el zelo de la salvaciō de los hombres, que el Apostol tenia, mayormente de aquellos que segun la carne erā sus hermanos, que haze un juramento solenne, trayēdo por testigo al Espiritu Sancto, en que declara la grādeza del dolor, y la tristeza continua, que padecia por la ceguedad dellos, y que tomara por partido ser el anathema de Christo, porq ellos se saluassen... ${ }^{38}$

Rápidamente se entiende que el Pablo que asume fray Luis es el Pablo polémico, evangelizador de los judíos. ${ }^{39}$ La intención sería profundizar de una manera positiva en las fuentes bíblicas, en nuestro caso, el Antiguo Testamento, para revelar los misterios contenidos en el mismo:

Con esta llaneza y claridad quize tratar esta materia... Y tambien, por que son tātas y tan claras las obras, y las señales que el Espiritu Sancto nos dexo en la sancta Escriptura, para conocer el Salvador, cuando viniesse, que una sola parte dellas basta para que la conozca, quien no estuuiere totalemente obstinado, y ciego. ${ }^{40}$

Es por esta razón, que el autor nos aclara desde el comienzo que «mas particularmente aprovechara esto a los que de la ley antigua han passado a la fe del Euangelio, que son muchos». ${ }^{41}$

A esto se suma la semejanza existente en lo relevante a método y estilo, entre el Scrutinium de Santa María y el tratado que nos ocupa. El Scrutinium se divide en dos secciones formadas por diálogos. En la primera, es el mismo Pablo quien discute con Saulo, figura representativa de Shlomo Halevi (su anterior identidad antes de la conversión), con la intención de mostrarle sus errores. La tarea se realiza de forma pacífica. De manera gradual, utilizando argumentos pertenecientes a las escrituras y fuentes posbíblicas,

36 Para este método en otros autores proconversos, véase Rosenstock 2002, 17, 22; Stuczynski 2012, 156-157, 170.

37 Para este antecedente en el obispo de Burgos, Stuczynski 2020, 112-115. También Domingo de Valtanás se vio estimulado por el apóstol: «A esto digo que es verdad, que he favorecido a esta gente. $Y$ el motivo que aquello tuve fue por parecerme que la ley de Jesucristo y la caridad así lo manda; y porque sé que San Pablo, a quien yo he tenido por mi padre, y aunque muy dificultosamente he tratado de imitar, asi lo hiciera», Valtanás 1963, 154 (la cursiva es mía). El mismo fray Luis retrata a su íntimo amigo Juan de Ávila, apóstol de Andalucía, como un gran imitador de San Pablo: «Asentado ya este fundamento, determinó buscar una guía á la que pudiese seguramente seguir, y no halló otra más conveniente que al apóstol San Pablo, dado por predicador de las gentes», Luis de Granada (Cuervo ed.) 1906, XIV: 221. Además, véase Huerga 1965, 247-291; Bataillon 2010, 217-220.

38 Luis de Granada 1583, 3.

39 Aunque luego se verá que el Pablo adoptado por el dominico pasa a ser el de los gentiles (universal e inclusivo).

40 Ídem.

41 Ibídem, 5. 
principalmente el Talmud, se convence a Saulo de que Jesús es el mesías prometido en ellas. Como se indicó anteriormente, la primera parte de la obra aquí tratada, sin implementar el coloquio, por razones retóricas y pedagógicas y centrándose casi exclusivamente en el Antiguo Testamento, contiene el mismo propósito. ${ }^{42}$ Respectivamente, las segundas secciones de los dos tratados exponen una serie de coloquios entre un maestro y su catecúmeno para aclarar ciertos misterios de la religión cristiana. A pesar de que los temas enfocados en los coloquios de la Cuarta parte varían de los tratados por Santa María, los dos llevan la advertencia implícita de que el bautismo del neófito necesita ser acompañado de un adoctrinamiento adecuado. Sin embargo, como mostraré más adelante, mientras que el diálogo mantenido en el Scrutinium fue hecho con la intención de empujar al cristiano viejo hacia la paciencia y caridad con su correligionario recién convertido (mensaje esbozado por fray Luis en la primera parte de su tratado), los coloquios de la Cuarta parte contienen un mensaje de paciencia, resignación y acatamiento para con los judeoconversos que encaja con la realidad sociopolítica del momento en que fueron redactados. Previo a adentrarnos en ellos, debe ser atendido otro motivo que atisbó en los párrafos ya citados: la ceguera teológica.

\section{Ceguera judaica versus CARIdAd CRISTIANA}

Explotado por Santa María y luego por otros autores proconversos, este residuo de la literatura polémica antijudía medieval es todo un leit motiv en la Cuarta parte. Sin esforzarnos, encontramos alusiones como la siguiente por toda la obra:

Pues q falta aqui sino poner testigos al cielo y a la tierra de la gloria de Dios, y de la obstinacion de los incredulos, pues el les dio tan claras señales para el conocimiento desta verdad: y ellos como asabiendas parece q cierran los ojos para no ver cosa mas clara q la luz del mediodia... confiesso q muchas vezes me esta llorando el coraçon viendo la estraña ceguedad q padece aquella parte q permanece obstinada en su error en medio de una tan clara luz. Quiten la niebla escura de la passiō q tienen ante los ojos y llamen con humildad a aquel señor $q$ es padre de las lumbres, y no es acceptador de personas, ni de linage, y el les abrira los ojos para q conozcā su Saluador, como ha abierto los de otros muchos q fielmente le siruen, adorā, y reconoscen. ${ }^{43}$

Las respuestas del catecúmeno son todavía más expresivas:

Agora que Dios me abrio los ojos, para ver la luz de la verdad veo mas clara la falsedad, y el engaño en que

42 Creo que el dominico no utilizó el diálogo para no tener que aplicar la interpretación judeorabínica a las profecías expuestas. Estoy de acuerdo con Resina Rodrigues (1988, 382-383) en que la obra carece del método de disputa que caracteriza el rubro. De esta manera, se refuerza su rol catequizador, y no menos importante en palabras del autor: "no desayunamos aquí a nadie de errores que no sepa» Luis de Granada $(1583,4)$. Es por esta razón, y el contexto anteriormente explicado, que la Cuarta parte emplea exclusivamente argumentos veterotestamentarios sin evocar fuente posbíblica alguna (e capítulo de los desvaríos, mentiras y falsedades del Talmud sería una excepción, véase aquí nota número 15 ).

43 Luis de Granada 1583, 95-96. La cursiva es mía. he viuido. Porque assi como los que han estado mucho tiempo en una carcel escura, y suzia, no sienten el mal olor della por estar habituados a el: mas lo que de nueuo vienen de ayres puros, y limpios, luego sienten este mal olor. ${ }^{44}$

Agora maestro quedo quieto, alegre, esforçado y consolado con el conocimiento tan claro destas verdades, de las quales pende toda mi bienauenturança y saluacion. Por lo qual doy muchas gracias al padre de las lumbres: pues el por el ministerio de vuestra doctrina ha alūbrado y quietado mi espiritu. ${ }^{45}$

Como podemos ver, frente al motivo de la ceguera se modela la idea de Cristo como señor de las lumbres, esto es, la fe como luz iluminadora. ${ }^{46}$ La ceguedad de la que fray Luis acusa a los judíos es puramente teológica, paulina. Esta fue impuesta en sus corazones y no en su mente. Ellos no poseen la luz para entender espiritualmente las escrituras. Sin embargo, es por medio de su ceguera, y a través del sufrimiento causado por esta, que las naciones descubrieron y vieron cumplirse el Evangelio. De esta manera, fray Luis devuelve al judío a una esfera puramente teleológica. De otra forma, no son los argumentos escolástico-racionales los esgrimidos frente a los cristianos nuevos: la lumbre para curar su ceguera yace en la fe, y no en la razón, tópico desplegado en la tercera parte de su Introducción.

Todavía más, como aludí anteriormente, el monje actúa como ajeno a la revolución que tuvo lugar en la polémica antijudía en las últimas centurias del medioevo ${ }^{47}$ Este antijudaísmo puro, que trata a un judío ciego (pero no inhumano, ya que tiene la capacidad para entender), sin rabinos y fuente posbíblica alguna, aleja al dominico del antisemitismo acercándolo a una visión más compasiva hacia con los judíos y el judaísmo: «Por tanto ya que tenemos acerca desto tan claro testimonio del Propheta, no ay razon para disputar, sino para llorar la ceguedad de la gente que con tan claro testimonio no le convence». ${ }^{48}$

Junto con esto, se refuerza nuestra hipótesis de que el texto se dirige e intenta acercarse lo más posible, por medio de un judío virtual, a la realidad de los judeoconversos.

Ahora bien, concentrémonos en el argumento en sí. Es la ceguera la causa del sufrimiento del judío, y no precisamente un defecto hereditario. Quiero decir, ellos en su obstinación cierran su corazón a la luz que Jesús les ofrece. El impedimento, esa ceguera que no les permite ver la luz, se puede reparar, curar. ${ }^{49}$ No habría solución si el obstáculo fuese su sangre, como se argumentaba en la sociedad ibérica de finales del siglo XVI.

No debemos olvidar que Albert Sicroff infirió que, en los años que nos ocupan, la polémica sobre el lugar de los

44 Ibídem, 114.

45 Ibídem, 205. La cursiva es mía.

46 Metáfora utilizada primeramente por Alonso de Cartagena en su Defensorium y luego por otros, Pastore 2010, 44, 79, 151.

47 Nos referimos al cambio argumentativo (innovative argumentation), Robert Chazan 1989, 67-85.

48 Luis de Granada $(1583,141)$ (sobre la profecía enunciada en Zac 9,9). Carente de contenido racista, degradante y antisemita, característico de los textos antijudíos de su tiempo, la Cuarta parte presenta una actitud barroca, que se logra guardar especialmente en los lugares críticos (como en la acusación deicida), donde otros autores polémicos pierden el control (y los modales). Cfr. Resina Rodrigues 1988, 390.

${ }^{49}$ Pudiendo tener esta sanación una connotación milagrosa (el ciego al que le regresa la vista). 
cristianos nuevos abandonó el aspecto teológico a favor de uno más político-social (técnico, práctico, racista). ${ }^{50}$ Esta secularización de la polémica llevó a que la pregunta, si la barrera para entrar en la sociedad cristiana (y a sus cargos) se debe a la ceguera de este pueblo, pierda su sitio. En su lugar, aparece el intento de los dos bandos de aumentar o disminuir los Estatutos, marcar el beneficio o dificultades que traían los mismos, cambiar la naturaleza de las investigaciones inquisitoriales (encuestas), o subir o bajar el número de las generaciones que se necesitaban para limpiarse de la sangre impura. Por el contrario, se puede apreciar que el dominico volvió a la esfera teológica y optó por disputar con un judío imaginario utilizando argumentos poco populares para su época. De otro modo, fray Luis recurrió a una terminología teológica antijudía clásica (ceguedad frente a luz) para no entrar en la terminología racista frecuente de su tiempo, que impedía la entrada a la cristiandad de los judíos, inclusive después de su bautismo. ${ }^{51}$ En el instante en que estos entiendan y reciban a Cristo como el mesías prometido en el Antiguo Testamento, tarea que la Cuarta parte aquí estudiada intenta efectuar, se les permitirá su entrada al cuerpo de Cristo. ${ }^{52}$ Como veremos, el dominico aborrece en su obra la política represiva inquisitorial, y se dilata de forma explícita contra los Estatutos de limpieza de sangre, dos cosas que, según Albert Sicroff, son inaceptables en aquellos años.

La solución para la ceguera del pueblo judío surge al terminar la primera sección del tratado. Es durante el relato de las atrocidades y calamidades «que padecierō los que no quisieron recebir nuestra sancta fe en tiempos de los Reyes catholicos Don Fernando y Doña Isabel» que la caridad y la preocupación por la salvación de las almas obliga al dominico

avisar a muchos falsamente zelosos de la fe: los quales tienen creydo, que no pecan, haziendo mal y daño a los que estan fuera della, ora sean moros, o ludios, o hereges, o Gentiles. Engañan se estos grandemente: porque también estos son proximos, como los fieles, segun se collige de aquella parabola del Saluador, que trata de la piedad y socorro del Samaritano con el herido. Y dado caso que nuestro Señor quiera castigar al infiel por sus peccados, y dipute ministros por quiē execute su yra, pero no menos peccan estos executores de la justicia diuina, que sino lo fuessen: porque instrumento fue de Dios el Rey de Babilonia para castigar su pueblo y destruyr su templo por los peccados de la gente (y assi lo llama Dios por Esayas, vara de furor, y baculo de su indignaciō) mas porque el no hazia esto por castigar las ofensas de Dios, sino por tiranizar la tierra, fue castigado con estrañas calamidades...Tal pues es el castigo de los que agrauian a sus proximos, aunque la diuina justicia se sirua dellos para castigo de los peccados, como a vezes tābien sirue para esto delos mismos demonios. ${ }^{53}$

50 Sicroff 2010, 199. Véase también Hernández Franco y Ruiz Ibáñez 2003, 36.

51 Para un razonamiento distinto véase Jones $(1999,328)$ : «A century after his death, the contribution of Paul of Burgos to the adversus Judaeos tradition reinforced the ancient stereotypes of obstinacy and blindness and contributed to making the sixteenth century a'black age in Jewish life».

52 Siendo el corpus misticus la metáfora predilecta de la sociedad cristiana, véase Kantorowicz 1957; Certeau 2006, 86-100. Dentro de la temática que nos ocupa, Stuczynski 2014, 253-275.

53 Luis de Granada 1583, 74-75.
Tomando a través de su pluma el papel de predicador, Luis de Granada aclara que la violencia y la represión, como la obrada por el Santo Oficio, no era la manera idónea de iluminar a los infieles. Muy por el contrario, lejos de castigar a los pecadores, los «executores de la justicia diuina» siembran el terror en la sociedad. No suficiente con esto, los «zelosos de la fe» terminan siendo comparados con los mismos demonios. ${ }^{54} \mathrm{Su}$ atrevimiento no termina aquí. El dominico aprovecha su excursus para brindar a su sociedad, dividida por el linaje y el orgullo de la sangre, una advertencia que suena como reprensión:

He dicho esto tan por extenso, para que se entienda que aunque Dios permita las vexaciones, y oppressiones de los incrédulos, y infieles, que permanecen en su error no menos peccan los que los maltratan, y vexan, que los que maltratan a sus proximos. Antes peccan mas grauemente: porque los escandalizan y hazē que tengan igual aborrecimiento a la ley, que a los professores de ella. Porque este odio es la causa principal, que los tiene obstinados en su engaño. De modo que aquella pared de diuision y de odio $q$ habia entre fieles y infieles (la cual Christo derribo, para amigarlos, y encoporarlos en su iglesia) muchos con sus malas obras y ejemplos la tornan a edificar. ${ }^{55}$

No se trata aquí solamente de un mensaje cristiano de amor al prójimo. El odio del que fray Luis previene a su christiano lector no es otro que el de los cristianos viejos hacia los nuevos, odio que desgarraba a la sociedad ibérica. Es la realidad histórica de la misma la que nos permite entender las vejaciones y opresiones como las ofensas, persecuciones y denuncias que tuvieron lugar contra la casta conversa. ${ }^{56}$ Esta animadversión, contraria a la fe y caridad cristiana, no solo es la causante de que los últimos sigan obstinados en su error, sino que contrasta con el mensaje paulino de una fe universal e inclusiva, erigiendo, nuevamente, la muralla que Cristo derribó por medio de su gracia.

Entonces, ¿cuál es el modo de aproximarlos y persuadirlos a la religión cristiana?

De lo dicho pues se infiere q la manera que se deuia tener para la conversiō de los infieles, es la que el Apostol (singular official deste officio) muestra que tenia, quando escriuiendo una carta a los de Thessalonica dize, Hezimonos como pequeñuelos en medio de vosotros, y como una ama que cria y regala sus hijos, teniendo os tan grande amor, que os quisiéramos dar, no solo el euangelio, sino tambien nuestras

\footnotetext{
54 Una opinión totalmente opuesta se encuentra en Huerga 1994, 276-277: «En un orden distinto, recordaré - conviene hacerlo- que fray Luis tuvo una idea más cabal que la idea negra que los historiadores se pasan unos a otros, sin crítica y sin demasiado fundamento: para la mayoría de los eruditos, la Inquisición fue un tribunal sanguinario; para fray Luis, sin callar sus rigores, fue un tribunal que obraba justicia mezclada con misericordia». En otro lugar: "Nada más que elogios tuvo siempre Fray Luis para la Inquisición, a pesar de que en tiempos de Valdés le hizo pasar amargos días; pero él no era un resentido; era un católico ferviente. Quizá nunca se haya hecho más subido encomio del Santo Oficio», Huerga 1959, 356.

55 Ibídem, 75.

56 Junto a la realidad del día a día, se encuentran los casos cercanos al dominico debido a su convivencia y conexión con agrupaciones de fuerte presencia conversa como la Compañía de Jesús, Juan de Ávila (y sus discípulos) y focos de «erasmistas-alumbrados», Huerga 1988b, 540-564; Bataillon 2010, 26-27, 55-58, 239.
} 
animas por la grandeza deste amor. Palabras son estas de grande consideracion, y que declaran muy bien las entrañas de charidad que este divino Apostol tenia con aquellos que de nuevo auian venido a la fe. ${ }^{57}$

No suficiente con esto, fray Luis parafrasea los primeros cinco versículos del capítulo noveno de la Epístola a los Romanos y remata de la siguiente manera: ${ }^{58}$

Hasta aquí son palabras del Apostol: el cual sentia tāto el perdimiēto de sus hermanos, q se offrecia a carecer de la gloria q esperaua de Christo (aunque no de su amor y gracia) porq sus hermanos gozassē della. Pues cō esta charidad, cō este zelo, cō estas entrañas de piedad cōuertierō los Apostoles el mūdo. ${ }^{59}$

Tomando nuevamente a Pablo como modelo y a sus epístolas como guía, Luis de Granada esgrime el emblema de la caridad para rechazar la política inquisitorial. Esta forma "dulce» de profesar el evangelio ya fue señalada por Stefania Pastore como la temática central de los tratados proconversos de finales del siglo XV y comienzos del XVI. En sus palabras, «cualquier reflexión acerca del valor de la caridad en la sociedad cristiana se convertía inmediatamente en el tema principal de la polémica pro conversa y anti-inquisitorial». ${ }^{60}$

La proximidad de la Cuarta parte a la teología proconversa que se desarrolló dentro la península Ibérica resulta manifiesta. Sin embargo, debemos recordar que a finales del siglo XVI esta hermenéutica no estaba en boga.

\section{HONRA, DESHONRA Y SANGRE PURIFICADORA}

En su estudio monumental Fray Luis de Granada y la literatura de espiritualidad en Portugal (1554-1632), la investigadora María Idalina Resina Rodrígues percibió en los diálogos 5, 6 y 7 de la Cuarta parte (que tratan sobre la vida amarga y la muerte deshonrosa de Jesús) la culminación del tratado. A su parecer, el dominico aprovecha su posición catequética en estos coloquios, que tratan sobre la persona de Cristo y su rol como salvador, para expresar su cosmovisión ascético-mística y para proporcionar, mediante la contemplación sobre la vida y sufrimiento del Mesías, un marco práctico, y no solo teológico, de cómo debe obrar el buen cristiano. Asimismo, ella considera que estos diálogos, más que los otros, entran en la polémica interreligiosa debido a que se concentran en la tensión existente entre el mesías temporal, esperado por los judíos, y el espiritual, encarnado en Cristo. ${ }^{61}$ Yo también reconozco en estos diálogos el punto máximo de la obra, pero a mi parecer ellos vienen a reflejar

57 Luis de Granada 1583, 75 (1 Tes 2, 7-8), la cursiva es mía.

58 «Pero mucho mas declaran esto las que escriue en la Epistola a los Romanos: las quales ponen espanto y admiracion a quienquiera q las lee: donde, con un solenne juramento dize assi, Verdad digo en Christo lesu no miento, dandome testimonio de esto mi consciencia, de la qual es testigo el espiritu sancto, que padezco una grā tris teza y continuo dolor en mi coraçon. Porque desseaua yo mismo ser anathema de Christo por la salud de mis hermanos, que son los hijos de Israel, deudos mios segū la carne: cuya era la adopcion de hijos, y la gloria, y el testamēto, y la ley, y el servicio, y las promesas diuinas: de cuyos padres nacio Christo segū la carne», Ídem.

59 Ídem.

60 Pastore 2010, 149-150.

61 Resina Rodrigues 1988, 405-406. algo diferente. Esto se debe a que, de forma paralela a la dicotomía que se acostumbra a crear en este tipo de tratados, entre el absurdo del mesías esperado por los judíos y el mesías verdadero ya venido, se encuentra en estos diálogos otra dicotomía: de honra y deshonra, dos conceptos opuestos que estaban estrechamente ligados a los Estatutos de limpieza de sangre. Conceptos que, en la sociedad dividida y segregada del dominico, tenían un sentido único y claro: la existencia de dos modelos de cristianos, el viejo (limpio en su sangre, puro y, como consecuencia, noble), y el nuevo (impuro, sucio y, como resultado, lleno de deshonra). A continuación, se sugerirá una hipótesis alternativa de la naturaleza y propósito de estos coloquios.

En el diálogo quinto, "que trata de la pobreza y humildad con la que el salvador vivio en el mundo», el dominico nos revela a un Cristo al que debemos tomar como ejemplo si queremos ser buenos cristianos, ya que él vivió para que podamos imitarlo. Fray Luis nos explica que el Mesías vino para arrancar "La primera rayz y fuente de cuantos peccados se comenten enel mūdo, el amor desordenado de si mismo». Puesto que de este es que nace el "amor desordenado de honra... sino poneos a cōtar quantas maneras de males, quātas guerras, quantos vandos, y dissensiones, quātos odios y inuidias aura causado en el mūdo este amor a la hōra». ${ }^{62}$ El buen cristiano debe amar con todo su corazón la deshonra e incluso buscarla, ya que solo a través de ella podrá alcanzar la perfección:

Pues siendo esto assi, que otra manera de vida auia de escoger aquel señor que venia a sanctificar, y beatificar los hombres, sino esta que auemos dicho, pobre, humilde y trabajosa, para que en ella viessen los amadores de la perfection, y de la verdadera felicidad que han de caminar por esta vereda, que el Salvador camino, amando la humildad, desseando la pobreza y abraçando los trabajos, sin los quales nadie llega a la cumbre de la perfectiō? ${ }^{63}$

Para poder alejarse y superar la persecución de la honra mundana (y acercarse así a la divina), debe el lector contemplar las vejaciones, sufrimientos y deshonras por los que Cristo transitó durante su vida, descritos en el sexto diálogo. Estos, nos explica el dominico, aprovechan para contrastar la naturaleza pecadora del hombre:

Pues uno de los principales fines a que el Salvador vino al mundo fue a sanctificar los hombres, y plantar en el (como dize el Apostol) un pueblo acepto a Dios seguidor de buenas obras, que es amador de toda virtud y sanctidad. Pero esta virtud que en el estado de inocencia (donde la naturaleza humana estaba pura y limpia) era muy facil y suave, despues de que ella se estrago y avinagro por el peccado no carece de dificultad. ${ }^{64}$

La temática del pecado original lleva al dominico, nuevamente, al problema principal de su sociedad: el amor propio. El buen cristiano debe luchar contra él, ya que siempre este viene acompañado de:

Ira, odio, temor, osadia y desconfianza las quales son crueles tyrannos que nos oprimen, cadenas que

62 Luis de Granada 1583, 135.
63 Ibídem, 136.

64 Ibídem, 142. 
prenden y verdugos que nos atormentan... Ellas perturban la paz de nuestras animas impidē nos el cuydado de nuestra salvacion y muchas vezes nos hazē tener por Dios la honra, y el dinero y el viētre: quando por el desordenado amor de estas cosas no tenemos de offender a nuestro Criador. 65

La lucha que el maestro describe ante su catecúmeno es perpetua, pero «como dize el Apostol los que son de Christo crucificaron su carne con todos sus vicios y cobdicias». ${ }^{66}$

Quiero proponer que la intención de estos diálogos fue crear una identificación con la realidad en la que se encontraban los judeoconversos contemporáneos al escritor, para de esta forma poder brindarles paz interna y espiritual, pero, más que nada, proveerles la honra que la sociedad les impedía. La situación en la que se hallaban los conversos, la persecución y denigración de su persona, la lejanía de las honras de la vida terrenal (Ilamémosla pública) y la deshonra y calumnias de la que eran víctimas, los convierte en el imitatio Christi perfecto. Junto con esto, no podemos obviar el mensaje esbozado por el dominico de amar la deshonra, un excelente eslogan en una sociedad formada por puros e impuros. ${ }^{67}$

Asimismo, la consolación final para los cristianos nuevos surge en el séptimo diálogo, «en el qual se declara, como en la muerte del Salvador, no solo no vuo ignominia, sino grandissima gloria». Por ser la Pasión una temática fundamental en la visión cristocéntrica del dominico, el coloquio más extenso de la copla es el que contiene su relato. Dividido en dos partes, la primera funciona como introducción teológica al misterio tratado. Con un intenso tono erasmiano, fray Luis relata la necesidad por la cual el Mesías optó por una muerte tan deshonrosa, sufrida y dolorosa. ${ }^{68}$ El maestro explica a su catecúmeno que Jesucristo se sacrificó para purificar con su sangre la humanidad, traspasándola a un estado puro y perfecto. Él no solo murió para limpiar nuestros pecados, sino para que no volvamos a cometerlos. ${ }^{69}$ Una vez introducido el catecúmeno en la materia, pasa a describirse el estado de la humanidad antes de la medicina celestial y el respectivo pase a la perfección que Cristo obró por medio de la

\section{Ibídem, 143.}

66 Ídem.

67 Juan Ignacio Pulido Serrano (2013, 339-369; 2014, 191-213) observó en Juan de Ávila la existencia de una sensibilidad teológica similar. No descartamos la posible influencia del último en el dominico.

68 Véase Bataillon 2013, 188-189, 208-209.

69 «Mas a lo dicho quiero acreecentar para mayor gloria deste mysterio: la cual es que no solo padeccio el para satisfazer las deudas de los peccados cometidos, sino tambien para alcançanrnos gracia por el merito y sacrificio de su sagrada passion, para que libres ya dellos viuiesemos en sanctidad de justicia delante de Dios [...] Y lo mismo significo el Apostol quando dixo, que siendo Christo crucificado, nuestro viejo hombre fue justamente con el crucificado: porque de ay adelante no sirvamos ya mas al peccado, ni estemos subjectos a el. Veys aqui pues otra causa de la passion del Salvador no menos gloriosa que la passada, porque aquella fue satizfazer por los peccados cometidos, y esta fue para alcançarnos gracia para no bolber a cometerlos», Luis de Granada 1583, 147. Este tipo de frases y planteamientos sobre el poder de la gracia, con referencia a la justificación por la fe, fueron advertidos, aunque en otras obras del dominico, por Marcel Bataillon (2013, 750-754). Se debería reconsiderar si las denuncias «clamorosas», y "esperpénticas», como objetó Huerga, de fray Alonso de la Fuente, de ser fray Luis el principal patrocinador de la epidemia alumbradista de Extremadura y Andalucía, fueron pura obsesión del primero, Huerga 1994, 273-275. «purificación de las animas». ${ }^{70}$ La razón del tal sacrificio, explica el maestro, puede coexistir solo en el amor infinito, caridad, bondad y misericordia de Cristo para con su cuerpo. A esto, se le dedica la segunda parte del coloquio.

Una vez enfocada la Pasión desde una perspectiva de fe, llega el tiempo de encarar el misterio desde su lado más sublime: la caridad. ${ }^{71}$ El dominico aprovecha la segunda parte de este coloquio para proveer al lector de una buena guía de contemplación y meditación de la pasión de Cristo, siendo caridad, fe y amor las tres palabras clave que lo adentran en ella. ${ }^{72}$ Todo el discurso se organiza en torno a la sentencia según la cual la bondad y santidad que Cristo quiso ofrecer fue la causa de su muerte gloriosa. Esto nos debe llenar de amor hacia él. Sin embargo, el maestro rápidamente aclara que será solo después de la muerte que uno podrá entender realmente el beneficio (y el amor infinito del creador) que se esconde detrás de su sagrado sacrificio. ${ }^{73}$ Mientras, lo que queda es aferrarse a su mensaje de bondad, misericordia y caridad, transmitido a través de su sufrimiento, e intentar seguir su obra y ejemplo, esto es, parecernos lo más posible a él:

Pues boluiendo al presupuesto principal, como sea propio de la bondad comunicarse a todos, y por consiguiente de la summa bondad dessear summamente comunicarse, por aquí entendereys la grandeza del deseeo, que el salvador tenia de esta communicacion, que es de hazernos buenos y sanctos, como el lo es. Esto es que imitemos en la pureza de la vida, en la simplicidad de las costumbres, en la charidad, y amor para con los proximos, y en la reuerencia y obediencia para con Dios, la condicion y innocencia de los Angeles. ${ }^{74}$

Por esta razón, fray Luis nos revela (con la ayuda de Pablo) que el Mesías eligió su muerte tan llena de sufrimiento y deshonra:

Pues fue tan grande el amor y desseo que aquel esposo celestial tuuo de comunicar a las animas esta tan gran pureza y hermosura, que viendo quan grandes estimulos y motiuos nos eran para esto sus dolores y tormentos, no dubdo offrecerse a ellos por esta causa. $Y$ esto es lo que el Apostol significo quando dixo, que poniendo el salvador ante sus ojos el gozo abraço la cruz, y no hizo caso de la mēgua y confusion que en ella

70 La tercera hazaña del presente tratado se expande amplia y específicamente sobre el pase a la perfección (ff. 35-47). Junto con Alonso de Oropesa y Juan de Valdés, fray Luis de Granada compartía «EI ideal de una Iglesia de santos y perfectos, unida por la fe en Cristo, el vínculo de caridad y el beneficio dado por Cristo para que la humanidad alcanzara una nueva vida y una nueva libertad», Pastore 2010, 272.

71 «Hasta aqui aueys tratado Maestro de lo que sirve para confirmaciō de nuestra Fe [...] mas porque el principal fruto de la doctrina es la charidad, querria que passassedes un poco las marcas de la doctrina, y que assi como aueys tratado de lo que toca a la luz del entendimiento, tratassedes tambien de lo que sirve para inflamar la voluntad en el amor de ese Clementisimo Redemptor», Luis de Granada 1583, 156.

72 Véase Pastore 2010, 292-293, 336.

73 «Mas la grandeza del beneficio no se puede enteramente conocer en esta vida. Porque assi como no podemos entender quan grande sea la gloria y hermosura de nuestro criador, hasta que lo veamos: assi tampoco la grandeza deste beneficio, hasta que en el cielo gozemos del principal fruto del, que es la gloria perdurable», Luis de Granada 1583,156 . Luego, el dominico parece entrar en un trance místico que lo lleva a dilatarse sobre los cantos de los ángeles en el cielo y las preciosas llagas de Cristo, señales de su sagrada pasión, ibídem, 156-159.

74 Ibídem, 163. 
auia de padecer. Pues que gozo es este, sino el alegria que aquella anima sanctisima auia de recebir cō la sanctificacion y hermosura de tantas animas, como auian de ser por la virtud y merito de su preciosa sangre, sanctificadas y hermoseadas? ${ }^{75}$

Es a través de esta sangre purificadora que fray Luis ofrece a los cristianos nuevos, en tiempos de violencia, persecución y discriminación, poner sus ojos en la pasión de Cristo, y de este modo sentir que ellos experimentan un poco la deshonra (que resulta ser honrosa) y sufrimiento que el Mesías padeció para su purificación. Esta purificación y «limpieza del anima» se efectúa reiteradamente durante el «sacramento de altar» con la entrada del cuerpo de Cristo en el creyente. Es por medio de esta "medicina celestial», de este "remedio divino", que las "animas» son consoladas por la "suavidad del redentor». Es aquí donde "se les aclara mas la fe y se fortalece la esperança, y se enciende con nuevos ardores de charidad $» .{ }^{76}$ No se podría esperar menos del que - como indica Luis de Granada - «es la misma pureza y limpieza». ${ }^{77}$

Más allá de las intenciones doctrinarias del dominico, a saber, procurar el acercamiento de los lectores a una fe espiritual compatible con su Weltanchaung cristiana, estos coloquios se realizaron para alentar y consolar al público converso, en una sociedad que estaba obsesionada con la honra. En otras palabras, a mi modo de ver, el propósito principal de estos coloquios es plantear un antídoto a la situación político-social impura y deshonrosa de los cristianos nuevos. Trayendo hacia el lector a un Cristo vivo y presente, el dominico da a la deshonra y al sufrimiento padecido por ellos un sentido positivo y redentor. ${ }^{78}$ Sin embargo, no se puede obviar, el mensaje dulce y conciliador ofrecido por el dominico es también uno de resignación, que, además, se encuentra incompleto. Solo con la entrada del creyente a las Ilagas de Cristo - esto es, luego de su muerte-, este ingresará en la verdadera bienaventuranza. ${ }^{79}$ Por ahora, lo

75 Ídem. El motivo de la sangre que «purifica las animas» es un mensaje que se repite dentro del tratado, véase el siguiente parecido: "y assi lo testifica el Apostol diziendo, Los que soys casados, amad vuestras mugeres como Christo amo la iglesia: por la qual se offrecio a la muerte: para que por el merito deste sacrificio la hermoseasse de tal manera, que no se hallase en ella macula ni ruga ni peccado. Pues por adornar las animas con esta tan grāde hermosura, no dubdo e offrecerse a todos los tormentos de su passion: para que acosta de las fealdades de su sacritissimo cuerpo, hermoseasse las animas cō esta tan grande gracia», ibídem, 42.

76 Luis de Granada 1583, 168. Véase que, junto a la fe y la caridad, ahora se suma la esperanza formando entre las tres un triángulo converso.

77 Ibídem, 174. El tema se despliega en el diálogo octavo, que por falta de espacio no podré elaborar.

78 Tanto Teresa de Cartagena como Pedro Díaz de Toledo reaccionaron de forma parecida en sus escritos, véase Giordano 2004, 51, 67. Para el caso de Juan de Ávila vuelvo a remitir a Pulido Serrano (2013, 339-369 y 2014, 191-213).

79 El catecúmeno también lo comprende de esta manera: «No puedo dexar de confessar Maestro: que todo esso que aveys dicho ha sido una musica suauisima para los oydos de mi anima y essa queria oyr todos los dias de mi vida. Porque que cosa mas dulce para un Christiano que verse tan preciado y tan amado de un tan grāde Dios, que se pusiesse a padecer todo ello por librarlo de las penas del infierno, y coronarle de perpetua gloria con los Angeles en el cielo, y atraerlo a su amor y obediencia con tan grande beneficio?», Luis de Granada 1583, 166. que les queda es sufrir, como sufrió su salvador por su purificación, e imitarlo en sus trabajos.

Por último, a raíz de lo dicho, se puede argumentar que se encuentra aquí implícitamente una crítica radical contra la discriminación de los Estatutos de limpieza de sangre. ${ }^{80}$ Esto, debido a que los cristianos nuevos, impuros en su descendencia, recibieron la purificación verdadera a través del Cristo crucificado. Más importante aún, parece que el converso, a pesar de su posición inferior en la sociedad, se encuentra más cercano a los preceptos e ideales cristianos, imita al Mesías de forma ejemplar a causa de su sufrimiento $y$, sobre todo, parece que, gracias a la deshonra de la que son víctimas, el señor les conceda la nobleza espiritual, nobleza que en la vida terrenal (pública) la sociedad ibérica se ocupaba de negarles.

Esta misma crítica, pero elaborada de manera más explícita, la encontramos finalizando el décimo diálogo, que trata de un motivo que ya fue analizado: «la ceguedad y miserias en la que viven la parte de los ludios, que no ha recibido la Fe del Salvador». Después del maestro haberle revelado a su catecúmeno las profecías que predijeron la ceguedad de la mayor parte de los judíos, haberlo advertido de que los nombres que aparecen en el Antiguo Testamento, como Israel, Jerusalén, monte Sion, casa de Jacob, o casa de David, se refieren tanto a los «buenos» (aquellos que se convirtieron), como a los «malos» (los que optaron por quedarse en la ley de Moisés), y haberle explicado que las desgracias y maldiciones que fueron anunciadas en la antigua ley se refieren a los que no recibieron al Mesías, y que las bendiciones y promesas en ella se refieren a los que sí creyeron en él, llega el punto culminante del coloquio. ${ }^{81}$

El intento del maestro de explicar a su catecúmeno la naturaleza y significado de los nombres que aparecen en la Sagrada Escritura destinados a llamar a los creyentes causan en él confusión, ya que después de haber recibido con sometimiento lo dicho pregunta a su maestro: "Mas una sola cosa me queda por preguntar: y es, si essas promessas diuinas que debaxo de essos nombres, pueblo de Israel, casa de lacob, con los demás que se promentē al pueblo de los ludios, pertenezcan ygualmente a los que creyeron de los Gentiles». ${ }^{82}$

Por el rumbo que toma el escrito, el catecúmeno parece entender que los cristianos verdaderos - o quizá la palabra adecuada sería ideales - no dejan de ser los convertidos de los judíos, y no los creyentes de los gentiles. De otra forma, el alumno parece entender que el cristiano es el judeoconverso, que ellos son el verdadero Israel, tanto en el espíritu como en la carne, y que el gentil ocupa un segundo plano. Para reparar este malentendido el maestro le responde: "Claro esta que la differencia de los linages y de sola la carne no aparta ni haze distincion en los ojos de Dios entre los que tienen la misma fe, la misma obediencia y el mismo espíritu». ${ }^{83}$

80 La crítica no distingue - o, mejor dicho, trasciende- las categorías y clases sociales en las que se encontraba dividida la sociedad del dominico.

81 Ibídem, 197-202. Analícese este tópico con mayor detenimiento en Kaplan Szyld 2019.

82 Ibídem, 203.

83 Ídem. 
En el momento de aceptar el credo, las diferencias entre pueblos, linajes y sangre desaparecen. El único parámetro es la fe en Cristo y su gracia. El énfasis paulino en la igualdad de los creyentes hace que las distinciones de casta se pierdan, de manera que no halla la forma de diferenciar los judíos que se convirtieron al cristianismo de los gentiles que recibieron a Cristo (o, en el tiempo y circunstancia del dominico, entre cristianos nuevos y viejos).

El diálogo no respondió a la materia prometida en su título, sino que tomó otro sendero. En lugar de tratar la cuestión de la «ceguera ludia», se concentró en responder la pregunta citada del catecúmeno a su maestro. De esta manera, fray Luis puso en boca de su catecúmeno la pregunta esencial que entonces se formulaba en torno al público judeoconverso en aquellos días. Si bien aquella pregunta podría haber pasado desapercibida por muchos de sus lectores, la respuesta contundente del maestro no deja lugar a dudas. Su respuesta dibuja una cristiandad limpia de discriminaciones étnicas. En ella, se articula la posición negativa de fray Luis frente a la persecución y segregación de los conversos, conductas percibidas por el monje como anticristianas.

De esta manera, mediante la utilización del género adversus iudaeos, en tiempos en que la polémica sobre el destino de los cristianos nuevos viró de una esfera propiamente teológica a otra más práctico-racial en España, y mientras que en Portugal se había optado por esperar que la solución llegase solo del cielo, Luis de Granada proponía una alternativa: catequizar y consolar con dulzura a los conversos, mostrando a sus lectores que sus vejaciones indicaban un camino de salvación y que el signo de su denigrante deshonra les asimilaba al rostro sufriente de Cristo. Por lo tanto, la Cuarta parte no fue una polémica imaginada contra un judío "virtual», como prometía, sino una apologética proconversa adaptada al tiempo y lugar en que se escribió. La obra tratada, centrándose en la pasión, amor y caridad de Cristo, recuperaba la aspiración pacificadora, inclusiva y universalista del pensamiento paulino, pasando a ser de esta manera una voz proconversa que no compartía la persecución obsesiva del Santo Oficio y menos aún la segregación étnica propiciada por los Estatutos de limpieza de sangre.

\section{FUENTES}

Arrais, Amador. 1604 (primera edición 1589). Dialogos de D.frey Amador Arraiz Bispo de Portalegre. Revistos e acrescentados pelo mesmo autor nesta segunda impressao. Em Coimbra: Na Officina de Diogo Gomez Loureyro Impressor da Universidade Com licenca do Sancto Officio, \& Ordinario \& Priuiligio Real. Anno do Senhor de M. DCIIII.

Balcells, José María. 1989. Introducción del símbolo de la fe. Madrid: Cátedra.

Barros, Joâo de. 1950. Diálogo evangélico sobre os artigos da fé contro o Talmud dos Judeus: manuscrito inédito, Introduçâo e notas de I. S. Révah. Lisboa: Livraria Studium.

Barros, Joâo de. 1983. Ropica Pnefma: Reprodução Fac-Similada Da Edição De 1532; Leitura Modernizada, Notas E Estudo De I. S. Révah. 2 vols. Lisboa: Instituto nacional de investigacao cientifica.

Costa Gomes, Ana Cristina. 2012. Diogo de Sá no Renascimento português. 2 vols. Lisboa: Centro de Estudos Clássicos da Faculdade de Letras da Universidade de Lisboa.

Luis de Granada. Quarta parte de la Introduction al symbolo de la fe: en la qual (procediendo por lumbre de fe) se trata del mysterio de nuestra Redemption: para lo cual se traen todas las prophecias, que testifican ser Christo nuestro salvador el Mesias prometido en la ley, donde también se declaran otros misterios, y artículos de nuestra Santa Fe, contenidos en el símbolo, Compuesta por el R.P Maestro F. Luys de Granada de la Orden de Sancto Domingo. Salamanca: por los Herederos de Mathias Gast: M.D LXXXIII.

Luis de Granada. 1906-1908. Obras de fray Luis de Granada. Edición de Justo Cuervo O.P. 14 vols. Madrid: Imprenta de la Viuda é Hija de Gómez Fuentenebro.

Santa Fé, Jerónimo. 2014. Tratado que fez mestre Jerónimo, médico do papa Bento XIII, contra os judeus em que prova o Messias da lei ser vindo: impresso em Goa por João de Endem, AOS 29 DIAS MÊS DE SETEMBRO, DE 1565 ANOS, edición de Moisés Orfali. Lisboa: Biblioteca Nacional de Portugal.

Santa Fé Jerónimo. 1987. De ludaicis erroribus ex Talmut: tratado apologético de Jerónimo de Santa Fé. Edición de Moisés Orfali. Madrid: Instituto de Filología, Departamento de Estudios Hebraicos y Sefaradíes.

Valtanás, Domingo de. 1963. Apología sobre ciertas materias morales en que hay opinión y apología de la comunión frecuente. Editado por Álvaro Huerga y Pedro Sainz Rodríguez. Barcelona: Juan Flors.

Vieira, Mildred E. y Frank Talmage. 1977. The mirror of the new Christians $=$ (Espelho de Christãos novos) of Francisco Machado (1550). Toronto: Pontifial Institute of Mediaval Studies.

\section{BiBLIOGRAFÍA}

Alonso del Campo, Urbano. 2005. Vida y obra de Fray Luis de Granada. Salamanca: Editorial San Esteban.

Alsina Calves, José. 1999. "Las ideas anatómicas de Fray Luis de Granada en la primera parte de la Introducción del Símbolo de la Fe». Llull 22: 337-345.

Asensio, Eugenio. 2000. El erasmismo y las corrientes espirituales afines: conversos, franciscanos, italianizantes. Salamanca: Seminario de Estudios Medievales y Renacentistas.

Austin, John Langshaw. 1955. Cómo hacer cosas con palabras. Escuela de Filosofía Austin, John Langshaw. 1955. Cómo hacer cosas con palabras. Santiago: Escuela de Filosofía Universidad ARCIS. http:// revistaliterariakatharsis.org/Como_hacer_cosas_con_palabras.pdf

Azevedo, João Lúcio de. 1922. História dos cristãos-novos portugueses. Lisboa: Livraria Clássica Editora.

Baião, António. 1906. A inquisição em Portugal e no Brasil: subsídios para a sua historia. Lisboa: OF.TIP. Calçada do Cabra.

Bataillon, Marcel. 2010. Los jesuitas en la España del siglo XVI. Valladolid: Fondo de Cultura Económica

Bataillon, Marcel. 2013. Erasmo y España: estudios sobre la historia espiritual del siglo XVI. México D. F.: Fondo de Cultura Económica.

Bodian, Miriam. 2007. Dying in the law of Moses: crypto-Jewish martyrdom in the Iberian world. Bloomington: Indiana University Press.

Borges, Célia Maia. 2009. «As Obras de Frei Luís de Granada e a espiritualidade de seu tempo: a leitura dos escritos granadinos nos séculos XVI e XVII na península ibérica». Estudios Humanísticos. Historia 8: 135-149.

Caro Baroja, Julio. 2000-2005. Los judíos en la España moderna y contemporánea. 3 vols. Madrid: Istmo.

Certeau, Michel. 2006. La fábula mística: siglos XVI-XVII. Madrid: Siruela.

Chazan, Robert. 1989. Daggers of faith: thirteenth-century Christian missionizing and Jewish. Berkeley: University of California Press.

Cohen, Jeremy. 1982. The Friars and the Jews: The Evolution of Medieval Anti-Judaism. Ithaca and London: Cornell University Press.

Cohen, Jeremy. 1999. Living letters of the law: ideas of the Jew in medieval Christianity. California: University of California Press.

Dadson, Trevor John. 1998. Libros, Lectores y Lecturas: Estudios sobre bibliotecas particulares españolas del siglo de oro. Madrid: Arco Libros.

Feitler, Bruno. 2015. «The Imaginary Synagogue: Anti-Jewish Literature in the Portuguese Early Modern World (16th-18 ${ }^{\text {th }}$ Centuries)». The Medieval and Early Modern Iberian World 61. Leiden - Boston: Brill. 
Fernández García, María de los Ángeles. 1995. «Criterios inquisitoriales para detectar al marrano: los criptojudíos en Andalucía en e siglo XVI». En Judios, Sefarditas, Conversos: La expulsión de 1492 y sus consecuencias: ponencias del Congreso Internacional celebrado en Nueva York en noviembre de 1992, ed. Ángel Alcalá, 478502. Valladolid: Ambito.

Figueirôa Rêgo, João. 2011. "Ahonra alheia por um fio». Os estatutos de limpeza de sangue nos espaços de expressão ibérica (sécs. XVIXVIII). Lisboa: Fundação Calouste Gulbenkian.

Gallego Morrel, Antonio. 1993. «Fray Luis y el diminutivo». En Fray Luis de Granada, su obra y su tiempo. Actas del congreso internaciona Granada 27-30 septiembre 1988, ed. Antonio García del Moral y Urbano Alonso del Campo, vol. 1, 231-235. Granada: Universidad de Granada.

García García, Rafael. 2016. «La apologética en la "Introducción del Símbolo de la Fe" de fray Luis de Granada». Scripta Theologica 48 (3): 611-638.

Giordano, Maria Laura. 2004. Apologetas de la fe: élites conversas entre Inquisición y patronazgo en España, siglos XV y XVI. Madrid: Fundación Universitaria Española.

Giordano, Maria Laura. 2018. "Como águilas nos avemos de renovar: Beneficio de Cristo Y Reforma de la Iglesia en Hernando de Talavera (1475-1507)». eHumanista /Conversos 6: 94-110.

Gitlitz, David M. 1996. Secret and deceit: the religion of the crypto-Jews. Philadelphia: The Jewish Publication Society.

Hernández Franco, Juan. 1996. Cultura y limpieza de sangre en la España moderna: puritate sanguinis. Murcia: Universidad de Murcia.

Hernández Franco, Juan. 2011. Sangre limpia, sangre española: el debate sobre los estatutos de limpieza (siglos XV-XVII). Madrid: Cátedra.

Hernández Franco, Juan y José Javier Ruiz Ibáñez. 2003. «Conflictividad social en torno a la limpieza de sangre en la España Moderna». Investigaciones Históricas 23: 35-56.

Huerga, Álvaro. 1949. «Fray Luis de Granada en Escalaceli». Hispania 36: 434-479,

Huerga, Álvaro. 1950. «Fray Luis de Granada en Escalaceli». Hispania 39: 297-335.

Huerga, Álvaro. 1959. «El proceso inquisitorial de la «Monja de Lisboa〉 y Fray Luis de Granada». Hispania sacra 12: 333-356.

Huerga, Álvaro. 1965. «El Beato Ávila, imitador de san Pablo». Teología espiritual 9: 247-291.

Huerga, Álvaro. 1988a. Fray Luis de Granada: una vida al servicio de la Iglesia. Madrid: Biblioteca de Autores Cristianos.

Huerga, Álvaro. 1988b. «Fray Luis de Granada entre mística, alumbrados e inquisición». Angelicum 65 (4): 540-564.

Huerga, Álvaro, ed. 1989. Tres estudios sobre fray Luis y una crónica de su IV centenario en Granada. Granada: Diputación Provincial de Granada.

Huerga, Álvaro. 1994. Historia de los Alumbrados: (1570-1630) V: Temas y personajes. Madrid: Fundación Universitaria Española.

Ingram, Kevin. 2009. "Historiography, historicity and the Conversos». En The Conversos and Moriscos in Late Medieval Spain and Beyond volume 1: departures and changes, ed. Kevin Ingram, 335-356. Leiden - Boston: Brill

Jones, Gareth. Lloyd. 1999. «Paul of Burgos and the Adversus Judaeos Tradition». HENOCH 21 (3): 313-330.

Kantorowicz, Ernst H. 1957. The king's two bodies: a study in mediaeval political theology. Princeton: Princeton University Press.

Kaplan Szyld, Axel. 2018. «¿Un Catecismo “pro-Converso” Camuflado?: La Cuarta Parte de la Introducción del Símbolo de la Fe de Fray Luis de Granada». En Escrituras Silenciadas, heterodoxias y disidencias en la península ibérica y América, ed. José F. Forméis Casals, Paulina Numhauser y Moisés Orfali, 213-230. Madrid: Universidad de Alcalá.

Kaplan Szyld, Axel. 2019. «Motivos judeo-cristianos en el pensamiento de Fray Luis de Granada (1504-1588)». Cadernos de Estudos Sefarditas 20: 81-99.

Liebman, Seymour B. 1970. The Jews in New Spain: faith, flame and the inquisition. Coral Gables: University of Miami Press.
Llamas Inglés, Aurora. 1998. El proceso didáctico de la «Introducción del símbolo de la fe» de Fray Luis de Granada. Madrid: Fundación Universitaria Española.

Llorente, Henar Pizarro. 2004. Un gran patrón en la Corte de Felipe II Don Gaspar de Quiroga. Madrid: Comillas.

Marcocci, Giuseppe. 2004. I custodi dell'ortodossia: inquisizione e Chiesa nel Portogallo del Cinquecento. Roma: Edizioni di storia e letteratura.

Marcocci, Giuseppe y José Pedro Paiva. 2016. História da Inquisição portuguesa (1536-1821). Lisboa: A Esfera dos Livros.

Martínez de Bujanda, Jesús. 2016. El índice de libros prohibidos y expurgados de la Inquisición española (1551-1819): evolución y contenido. Madrid: Biblioteca de Autores Cristianos.

Maryks, Robert. A. 2010. The Jesuit Order as a synagogue of Jews: Jesuits of Jewish ancestry and purity-of-blood laws in the early Society of Jesus. Leiden - Boston: Brill.

Pastore, Stefania. 2010. Una herejía española: conversos, alumbrados e Inquisición (1449-1559). Madrid: Marcial Pons.

Praena Segura, Antonio. 2005. «La belleza de predicar. Consideraciones estéticas en el lenguaje de fray Luis de Granada». Communio 38 (1): 107-143.

Pulido Serrano, Juan Ignacio. 2013. «Juan de Ávila: su crítica a la limpieza de sangre y su condición conversa». Sefarad: Revista De Estudios Hebraicos Y Sefardíes 73 (2): 339-369. https://doi. org/10.3989/sefarad.013.011

Pulido Serrano, Juan Ignacio. 2014. «Experiencia Vital y Elaboración de una Fórmula Conciliadora en la Obra de Juan de Ávila». En El maestro Juan de Ávila (1500?-1569): un exponente del humanismo reformista, edición de M. a Dolores Rincón González, Raul Manchón Gómez y Juan Esquerda Bifet, 191-213. Madrid: Fundación Universitaria Española.

Resina Rodrigues, María Idalina. 1979. «Literatura e anti-semitismo: séculos XVI e XVII». Brotéria 109: 41-56, 137-153.

Resina Rodrigues, María Idalina. 1988. Fray Luis de Granada y la literatura de espiritualidad en Portugal (1554-1632). Madrid: Universidad Pontificia de Salamanca, Fundación Universitaria Española.

Rosenstock, Bruce. 2002. New Men: Conversos, Christian Theology, and Society in Fifteenth Century Castile. London: University of London.

Saraiva, António José. 2001. The Marrano Factory: The Portuguese Inquisition and Its New Christians 1536-1765. Traducido, revisado y aumentado por Herman Prins Salomon y I.S.D. Sassoon. Leiden - Boston: Brill.

Sicroff, Albert A. 2010. Los estatutos de limpieza de sangre: controversias entre los siglos XV y XVII. Newark: Juan de la Cuesta.

Skinner, Quentin. 2002. Visions of Politics, Volume 1: regarding method. Cambridge: Cambridge University Press.

Stuczynski, Claude B. 2012. "Pro-Converso Apologetics and Biblical Exegesis». En The Hebrew Bible in fifteenth-century Spain: exegesis, literature, philosophy, and the arts, ed. Jonathan Decter y Arturo Prats, 151-177. Leiden - Boston: Brill.

Stuczynski, Claude B. 2014. "To Theology and Politics: Alonso de Cartagena and the Conversos within the 'Mystical Body'». En Conflict and religious conversation in Latin Christendom 17: studies in honor of Ora Limor, ed. Israel. J. Yuval y Ram Ben-Shalom, 253275. Brepols Publishers.

Stuczynski, Claude. B. 2015. "Anti-Rabbinic Texts and Converso Identities: Fernão Ximenes de Aragãos Catholic Doctrine». En The Conversos and Moriscos in Late Medieval Spain and Beyond, ed. Kevin Ingram y Juan Ignacio Pulido Serrano, 3, 63-94. Leiden Boston: Brill.

Stuczynski, Claude. B. 2020. "Converso Paulinism and Residual Jewishness: Conversion from Judaism to Christianity as a Theological-Political Problem». En Bastards and Believers: Converts and Conversion between Judaism and Christianity, ed. Pawel Maciejko y Theodor Dunkelgrün, 112-134. Philadelphia: University of Pennsylvania Press. 
Talmage, Frank. 1981. «To Sabbatize in Peace: Jews and New Christians in Sixteenth-Century Portuguese Polemics». The Harvard Theological Review 74 (3): 265-285.

Valladares, Rafael. 2008. La conquista de Lisboa: Violencia militar y comunidad política en Portugal, 1578-1583. Madrid: Marcial Pons

Vizán, Blanca. 2013. «Lecturas criptojudías y la Introducción al Símbolo de la Fe de fray Luis de Granada». Studia aurea monográfica 5 : 195-216.
Yisraeli, Yossi. 2014. "Between Jewish and Christian scholarship in the fifteenth century: the consolidation of "converso doctrine" in the theological writings of Pablo de Santa Maria». Ph.D. diss. University of Tel-Aviv. 